\title{
miR-21 promotes $\alpha$-SMA and collagen I expression in hepatic stellate cells via the Smad7 signaling pathway
}

\author{
RONG-QUAN FU, DAN-PING HU, YI-BING HU, LIANG HONG, QING-FENG SUN and JI-GUANG DING \\ Department of Infectious Diseases, The Third Affiliated Hospital of Wenzhou Medical University, \\ Rui'an, Zhejiang 325200, P.R. China
}

Received June 23, 2016; Accepted April 20, 2017

DOI: $10.3892 / \mathrm{mmr} .2017 .7054$

\begin{abstract}
The aim of the present study was to investigate the role of microRNA (miR)-21 in regulating collagen I and Smad7 expression in activated rat hepatic stellate cells (HSCs). Rat HSCs were isolated by single-step density gradient centrifugation with Nycodenz. Cellular content of miR-21, SMAD7, $\alpha$-smooth muscle actin $(\alpha-S M A)$, collagen type I alpha 1 (COLLA1) and COLL alpha 2 (A2) mRNA was examined by reverse transcription-quantitative polymerase chain reaction (RT-qPCR), and cellular content of Smad7 and $\alpha-S M A$ protein was detected by western blotting. Binding of miR-21 to the 3'-untranslated region (UTR) of Smad7 was verified by dual-luciferase assay. The authors observed that, in activated HSCs, expression of miR-21 was significantly increased in a time-dependent manner, while expression of Smad7 mRNA and protein was significantly reduced. In addition, miR-21 mimics significantly enhanced cellular $\alpha$-SMA mRNA and protein content, while miR-21 inhibitor significantly reduced $\alpha$-SMA mRNA and protein levels. Similarly, cellular content of COLLA 1 and COLLA2 mRNA was significantly elevated by miR-21 mimics, but reduced by miR-21 inhibitor, in activated HSCs. Moreover, cellular content of Smad7 mRNA and protein was significantly reduced by miR-21 mimics, but significantly increased by miR-21 inhibitor. Furthermore, miR-21 mimics activated firefly luciferase in HEK293 cells transfected with the wild type 3'-UTR of Smad7. miR-21 regulates expression of $\alpha$-SMA and collagen I in activated rat HSCs by directly targeting Smad7.
\end{abstract}

Correspondence to: Professor Ji-Guang Ding, Department of Infectious Diseases, The Third Affiliated Hospital of Wenzhou Medical University, 108 Wansong Road, Rui'an, Zhejiang 325200, P.R. China

E-mail: djg5011@163.com

Key words: microRNA-21, collagen I, $\alpha$-smooth muscle actin, Smad7, hepatic stellate cells

\section{Introduction}

The primary cause of liver fibrosis is chronic inflammation, which is characterized by excessive scarring (1). In response to chronic liver injury and inflammation, fibrogenic precursor cells, hepatic stellate cells (HSCs), transdifferentiate into fibrogenic myofibroblasts $(1,2)$. An array of cytokines contribute to transdifferentiation of HSCs, of which transforming growth factor (TGF)- $\beta 1$ is an important profibrogenic cytokine that accelerates fibrosis by triggering proliferation and differentiation of HSCs into myofibroblasts, a process termed HSC activation $(3,4)$. Activation of HSCs by TGF- $\beta$ is usually accompanied by increased synthesis, and decreased degradation, of ECM proteins, in particular collagen I and II (5). Smad7 is an important feedback inhibitor of TGF- $\beta$ signaling (6). TGF- $\beta$ induces phosphorylation of Smad $2 / 3$ and Smad4, which in turn upregulates Smad7 transcription (7). Excess Smad7 forms a stable complex with the activated type I receptor, thereby preventing Smad phosphorylation, and subsequent downstream events (8). Smad7 is a potential master transcriptional repressor of HSC transdifferentiation. Smad7 overexpression in the liver has been demonstrated to inhibit phosphorylation of Smad2/3 and expression of collagen I, thus protecting against HSC activation and liver fibrosis (9). Conversely, epigenetic repression of Smad7 by DNA methylation promotes HSC activation and liver fibrosis in rats (3).

MicroRNAs (miRs) are endogenous, non-coding single-stranded RNAs of 18 to 24 nucleotides that negatively regulate gene expression by binding the 3'-untranslated region (UTR) of target mRNAs (10). Dysregulation of miRs is associated with a variety of diseases, including cancer and liver fibrosis $(1,11)$. miR-21 is ubiquitously expressed, and was identified as being highly upregulated in most types of cancer (12). Elevated levels of miR-21 were previously reported to be associated with initiation of myocardial, renal and pulmonary fibrosis $(13,14)$. miR-21 expression is stimulated during fibrosis by profibrogenic TGF- $\beta$. TGF- $\beta$ induces phosphorylation of Smad 2 and 3 (R-Smads), which can interact with the p68 RNA helicase of the Drosha/PDCD4 microprocessor complex, suppressing the transformation of pri-miR-21 into the precursor pre-miR-21 (15). In response to TGF- $\beta$ stimulation, transcriptional upregulation of miR-21 is reported to be mediated by activation of Smad-3 rather than Smad-2 (16). Moreover, different patterns of miRNA expression were observed in 
chronic liver diseases of various etiologies. Overexpression of miR-21 was recently reported to promote activation of human hepatic stellate LX-2 cells, while downregulation of miR-21 blocked activation of these cells, suggesting that miR-21 may also have a direct fibrogenic effect in the liver (17). Although high levels of miR-21 expression are associated with the onset of liver fibrosis $(18,19)$, the effect of miR-21 on liver fibrosis is remains elusive.

Interestingly, miR-21 was recently hypothesized to regulate synthesis of TGF- $\beta$ inhibitory Smad7 protein (20). However, a direct interaction between miR-21 and Smad7 has rarely been reported in fibrogenic conditions. Smad7 has been reported to inhibit type I collagen expression, but evidence that the expression of collagens is regulated by miR-21 in HSCs is still lacking. In the present study, therefore, the authors investigated the effect of miR-21 on the expression of type I collagen mRNA and protein in rat HSCs, and further investigated the role of $\mathrm{Smad} 7$ in this regulation.

\section{Materials and methods}

Animals and reagents. Male Sprague-Dawley (one year-old) rats (weight, 500-600 g) were provided by the Experimental Animal Center of Wenzhou Medical University (Rui'an, China). All rats were housed at $21 \pm 1^{\circ} \mathrm{C}$, with $55 \pm 15 \%$ humidity and a dark/light cycle of $12 / 12 \mathrm{~h}$, and provided access to food and water ad libitum. The experimental protocols were reviewed and approved by the Ethics Committee of Wenzhou Medical University (Rui'an, China).

Fetal bovine serum (FBS) and high-glucose Dulbecco's modified Eagle medium (DMEM) were purchased from Gibco; Thermo Fisher Scientific, Inc. (Waltham, MA, USA). Lipofectamine ${ }^{\circledR} 2000$ and the RevertAid RT Reverse Transcription kit were purchased from Invitrogen; Thermo Fisher Scientific, Inc. The RNApure Total RNA kit was purchased from Aidlab Biotechnologies Co., Ltd. (Beijing, China). Scramble miRNA, miR-21 inhibitor and miR-21 mimics were synthesized by Shanghai GenePharma Co., Ltd. (Shanghai, China). SacI and HindIII restriction enzymes were purchased from New England Biolabs, Inc. (Ipswich, MA), dual-Luciferase Reporter Assay kit and passive lysis buffer from Promega Corporation (Madison, WI, USA), and SYBR-Green real-time PCR Master Mix was obtained from Toyobo Co., Ltd. (Osaka, Japan). Antibodies against Smad7, $\alpha$-smooth muscle actin ( $\alpha$-SMA) and $\beta$-actin were purchased from Oncogene Science Diagnostics (Cambridge, MA, USA), horseradish peroxidase (HRP)-conjugated goat anti-rabbit secondary antibody from Santa Cruz Biotechnology, Inc. (Dallas, TX, USA), and the enhanced chemiluminescence (ECL) system from Thermo Fisher Scientific, Inc.

Isolation and culture of HSCs. HSCs were isolated as previously described, with minor modifications (21). Briefly, the rats were anesthetized by intraperitoneal injection of $54 \mathrm{mg} / \mathrm{kg}$ sodium pentobarbital. A small piece (100-200 mg) of liver tissue was excised using scissors and digested in $1 \mathrm{ml}$ digestion solution containing $0.5 \mathrm{mg} / \mathrm{ml}$ pronase $\mathrm{E}, 0.6 \mathrm{mg} / \mathrm{ml}$ collagenase and $0.1 \mathrm{mg} / \mathrm{ml}$ deoxyribonuclease (from the bovine pancreas, Grade II, Boehringer Ingelheim GmbH, Ingelheim, Germany) dissolved in Gey's balanced salt solution (GBSS) for $45 \mathrm{~min}$ at $37^{\circ} \mathrm{C}$. The cell suspension was centrifuged at $450 \mathrm{x} \mathrm{g}$ for $6 \mathrm{~min}$ at $4^{\circ} \mathrm{C}$. The cell pellet was resuspended in $15 \mathrm{ml}$ GBSS containing $3 \mathrm{~g} / \mathrm{l}$ bovine serum albumin and mixed with $12.5 \mathrm{ml}$ $28.7 \%$ (w/v) of Nycodenz (Nycomed, Zurich, Switzerland) in GBSS without $\mathrm{NaCl}$. The mixture was centrifuged at $1,400 \mathrm{xg}$ for $20 \mathrm{~min}$ at $4^{\circ} \mathrm{C}$. Then the white, diffuse band overlaying the Nycodenz cushion was gently aspirated, diluted in $40 \mathrm{ml}$ GBSS and centrifuged at $450 \mathrm{x} \mathrm{g}$ for $7 \mathrm{~min}$ at $4^{\circ} \mathrm{C}$. The cell pellet was suspended and cultured in DMEM supplemented with L-glutamine (4 mmol/l), penicillin (100 IU/ml), streptomycin $(100 \mu \mathrm{g} / \mathrm{ml})$ and $10 \%$ FBS in a humidified atmosphere of $5 \% \mathrm{CO}_{2} / 95 \%$ air at $37^{\circ} \mathrm{C}$. The resultant cell suspension was determined, by vitamin A staining, to contain $>90 \%$ HSCs, and $95 \%$ of cells were determined be viable by trypan blue staining.

Activation of HSCs. HSCs were cultured for 3 days, then were considered static HSCs. Activated HSCs were obtained by incubation with $2 \mathrm{ng} / \mathrm{ml}$ TGF- $\beta 1$. For miR transfection, HSCs were seeded $\left(2 \times 10^{4}\right.$ cells/well) into 24 -well plates. At 10 days, $75 \mathrm{nM}$ scramble miRNA, miR-21 inhibitor or miR-21 mimics were transfected into HSCs using Lipofectamine ${ }^{\circledR} 2000$. At $48 \mathrm{~h}, \mathrm{HSCs}$ were washed with phosphate-buffered saline twice and lysed in $100 \mu \mathrm{l}$ passive lysis buffer (Beyotime Institute of Biotechnology, Haimen, China) for $15 \mathrm{~min}$. Whole cell lysate was collected by centrifugation at $12,000 \mathrm{x}$ g for $10 \mathrm{~min}$.

Construction of the luciferase reporter plasmid, transfection and dual-luciferase assay. The pMIR-reporter vector (Applied Biosystems; Thermo Fisher Scientific, Inc.) was used to construct a plasmid containing the 3'-UTR of Smad7. Targetscan software (version, 5.1; Whitehead Institute for Biomedical Research, Cambridge, MA, USA) was used for target prediction. The fragments containing the predicted wild (5'-GCUCACACUUUAAUAUAAGCUA-3', the region targeted by miR-21 is marked in bold) and mutated (5'-GCU CACACUUUAAUAUAUCGAA-3', the mutated sequences is marked in bold) sites were directly synthesized (Shanghai GenePharma Co., Ltd.), then subcloned into a pMIR-report vector by double digestion with SacI and HindIII. HEK293 cells, obtained from the Central Laboratory, First Affiliated Hospital of Wenzhou Medical University (Wenzhou, China), were cultured in DMEM supplemented with 10\% FBS and antibiotics. HEK293 cells $\left(2.0 \times 10^{5}\right)$ were seeded into six-well plates and cultured for $24 \mathrm{~h}$, then transfected with $700 \mathrm{ng}$ pMIR-reporter plasmids containing the wild or mutated 3'-UTR of Smad7 in combination with $400 \mathrm{nM}$ of miR-21 mimics or scramble miRNA using Lipofectamine ${ }^{\circledR} 2000$. After $48 \mathrm{~h}$ the cells were collected and luciferase activity was measured by Dual-Luciferase Reporter Assay kit using a TD20/20 Luminometer (Turner Designs, San Jose, CA, USA). Each experiment was performed in triplicate. The results were expressed as relative Renilla luciferase activity, normalized to firefly luciferase activity.

Detection of miR-21 expression by reverse transcriptionquantitative polymerase chain reaction ( $R T$ - $q P C R)$. Total RNA from rat HSCs was extracted by using RNApure Total RNA kit following the manufacturer's instructions. The first-strand cDNA was synthesized by stem-loop primers and RevertAid 
RT Reverse Transcription kit. qPCR of miR-21 was carried out using miR-21 specific primers (Table I) and SYBR-Green real-time PCR Master Mix on an ABI Prism 7500 machine (Thermo Fisher Scientific, Inc.) following the manufacturer's protocol. The level of U6 mRNA (Table I) was used as an internal control, and relative mRNA expression was calculated from three independent experiments. Thermocycling conditions were as follows: An initial predenaturation step for $5 \mathrm{~min}$ at $95^{\circ} \mathrm{C}$, followed by 30 cycles of denaturation at $94^{\circ} \mathrm{C}$ for $45 \mathrm{sec}$, annealing at $56^{\circ} \mathrm{C}$ for $45 \mathrm{sec}$ and extension at $72^{\circ} \mathrm{C}$ for $10 \mathrm{~min}$. The fold-change in $\mathrm{miR}-21$, relative to U6, was determined by the $2^{-\Delta \Delta \mathrm{Cq}}$ method (22).

Detection of SMAD7, $\alpha$-SMA, COLLA1, COLLA2 and GAPDH mRNA expression in HSCs using RT-qPCR. Total RNA extraction and first-strand synthesis were performed as described above. Specific primers for SMAD7, $\alpha-S M A$, COLLA1, COLLA2 and GAPDH were designed using Primer Premier software (Table I; version, 5.0; Premier Biosoft, Palo Alto, CA, USA), and synthesized by Takara Biotechnology Co., Ltd. (Dalian, China). PCR reaction conditions were optimized for each set of primers (Table I), and carried out as described above. The threshold cycle $(\mathrm{Ct})$ was determined and the fold-change in SMAD7, $\alpha$-SMA, COLLA1, COLLA2 mRNA levels were calculated, relative to GAPDH, using $\mathrm{Ct}$ values.

Western blotting. Protein concentration was determined using the bicinchoninic acid assay protein assay kit (Biorbyt, Ltd., Cambridge, UK). Whole-cell extracts $(60 \mu \mathrm{g})$ were fractionated by $8 \%$ SDS-PAGE, then transferred onto a polyvinylidene difluoride membrane (EMD Millipore, Billerica, MA, USA). The membranes were blocked in $5 \%$ nonfat milk/TBST (0.2\% Tween-20, $20 \mathrm{mmol} / 1$ Tris-HC1, $150 \mathrm{mmol} / 1 \mathrm{NaC} 1$, $\mathrm{pH}$ 7.4) for $2 \mathrm{~h}$ at room temperature, then incubated with the following primary antibodies: Smad7 (Wuhan Boster Biological Technology, Ltd., Wuhan, China; catalog no. BA1399), $\alpha$-SMA, (Abcam, Cambridge, UK; catalog no. ab4085) and $\beta$-actin (Boster Biological Technology; catalog no. BM0627; 1:200 dilution) overnight at $4^{\circ} \mathrm{C}$. After three washes in TBST, the membranes were incubated with HRP-conjugated goat anti-rabbit antibody (Abcam; catalog no. AB6721; 1:2,000 dilution) for $1 \mathrm{~h}$ at room temperature. Following extensive washing in TBST, staining of the blots was detected using the ECL system. (Thermo Fisher Scientific, Inc.). $\beta$-actin was used as the loading control. Image Lab version 4.1 software (Bio-Rad Laboratories, Inc., Hercules, CA, USA) was used for analysis.

Statistical analysis. Quantitative data are presented as means \pm standard deviation. The difference among different groups of cells was calculated by Student's t-test using SPSS software (version 17.0, Chicago, IL, USA). $\mathrm{P}<0.05$ was considered to indicate a statistically significant difference.

\section{Results}

TGF- $\beta 1$ upregulates miR-21 expression, but inhibits Smad7 expression, in rat HSCs. TGF- $\beta 1$ is a profibrogenic cytokine that induces HSCs activation $(3,4)$ and upregulates expression of miR-21 during fibrosis (15). In the present study, the authors first investigated the effect of exogenous TGF- $\beta 1$ on miR-21 expression in rat primary HSCs. Incubation with $2 \mathrm{ng} / \mathrm{ml}$ TGF- $\beta 1$ was indicated to significantly enhanced miR-21 expression, in a time-dependent manner $(\mathrm{P}<0.01$ or $\mathrm{P}<0.001)$. The effect was greatest 7 days following addition of TGF- $\beta 1$ (Fig. 1A). However, expression of Smad7 mRNA was significantly reduced in the presence of TGF- $\beta 1(\mathrm{P}<0.01$; Fig. 1B), and cellular content of Smad7 protein was also significantly reduced followings incubation with TGF- $\beta 1$ $(\mathrm{P}<0.01$; Fig. 1C).

miR-21 regulates expression of $\alpha$-SMA, COLLA1 and COLLA2 in activated HSCs. $\alpha$-SMA is a marker of myofibroblast formation (21). miR-21 mimics were previously reported to promote expression of $\alpha$-SMA, in addition to proliferation and invasion of the primary stromal cells of phyllodes tumors, whereas miR-21 antisense oligos inhibited these processes (23). To verify the differentiation of HSCs into myofibroblasts following TGF- $\beta 1$ stimulation, the authors measured the cellular content of $\alpha$-SMA mRNA and protein following incubation with miR-21 mimics or an inhibitor. In comparison to cells transfected with scramble miRNA, cells transfected with miR-21 mimics contained significantly higher levels of $\alpha$-SMA mRNA and protein, while miR-21 inhibitor significantly inhibited $\alpha$-SMA mRNA and protein expression in activated HSCs upon TGF- $\beta 1$ stimulation $(\mathrm{P}<0.01$; Fig. $2 \mathrm{~A}$ and $\mathrm{B}) . \mathrm{miR}-21$ is reported to promote collagen synthesis in high glucose-treated primary cardiac fibroblasts by targeting dual specific phosphatase 8 (24). miR-21 mimics were identified to significantly upregulated expression of COLLAI and COLLA 2 mRNA in activated HSCs $(\mathrm{P}<0.001)$, while the miR-21 inhibitor significantly suppressed their expression $(\mathrm{P}<0.01$; Fig. 2C).

miR-21 directly regulates expression of Smad7 in activated rat HSCs. miR-21 overexpression was recently reported to contribute to TGF- $\beta 1$-induced epithelial-to-mesenchymal transition (EMT) by inhibiting Smad7 (20). Moreover, Smad7 overexpression in the liver inhibits phosphorylation of Smad2/3 and collagen I expression (9). Thus, the authors hypothesize that Smad7 may interfere with the process by which miR-21 promotes collagen I expression in activated rat HSCs. Indeed, miR-21 mimics were observed to significantly reduce expression of Smad7 mRNA and protein in activated HSCs $(\mathrm{P}<0.01)$, while a miR-21 inhibitor significantly enhanced expression of Smad7 mRNA and protein $(\mathrm{P}<0.01$ or $\mathrm{P}<0.001$; Fig. $3 \mathrm{~A}$ and $\mathrm{B}$ ). These results suggested that miR-21 may regulate Smad7 expression in activated HSCs. To further investigate whether Smad7 is a direct target of miR-21, the authors cloned the wild type or mutated 3'-UTR of the Smad7 gene into a pMIR-report vector and overexpressed these plasmids in HEK293 cells. Furthermore, these cells were transfected with miR-21 mimics or scramble miRNA, and compared the Renilla and firefly luciferase activity in these cells. Firefly luciferase luminescence was quite low in these cells, and only elevated in cells transfected with the plasmid containing the wild type 3'-UTR of Smad7 and miR-21 mimics. Higher levels of firefly luciferase luminescence were detected in the cells transfected with plasmids containing the wild type 3'-UTR 
Table I. Specific primers for polymerase chain reaction.

\begin{tabular}{|c|c|c|c|}
\hline Name & Direction & Sequences & Size of products $(\mathrm{bp})$ \\
\hline miR-21 & $\begin{array}{l}\text { Forward } \\
\text { Reverse }\end{array}$ & $\begin{array}{l}\text { 5'-GCGGTAGCTTATCAGACTGA-3' } \\
\text { 5'-TGCGTGTCGTGGAGTC-3' }\end{array}$ & 63 \\
\hline U6 & $\begin{array}{l}\text { Forward } \\
\text { Reverse }\end{array}$ & $\begin{array}{l}\text { 5'-GCTTCGGCAGCACATATACTAAAAT-3' } \\
\text { 5'-CGCTTCACGAATTTGCGTGTCAT-3' }\end{array}$ & 89 \\
\hline Smad7 & $\begin{array}{l}\text { Forward } \\
\text { Reverse }\end{array}$ & $\begin{array}{l}\text { 5'-GGAGTCCTTTCCTCTCTC-3' } \\
\text { 5'-GGCTCAATGAGCATGCTTCAC-3' }\end{array}$ & 125 \\
\hline$\alpha-\mathrm{SMA}$ & $\begin{array}{l}\text { Forward } \\
\text { Reverse }\end{array}$ & $\begin{array}{l}\text { 5'-GTGCTGTCCCTCTATGCCTCTGG-3' } \\
\text { 5'-GGCACGTTGTGAGTCACACCATC-3' }\end{array}$ & 77 \\
\hline Col1A1 & $\begin{array}{l}\text { Forward } \\
\text { Reverse }\end{array}$ & $\begin{array}{l}\text { 5'-CCTGCCTGCTTCGTGTAAA-3' } \\
\text { 5'-TTGAGTTTGGGTTGTTGGTCT-3' }\end{array}$ & 100 \\
\hline Col1A2 & $\begin{array}{l}\text { Forward } \\
\text { Reverse }\end{array}$ & $\begin{array}{l}\text { 5'-TAAAGAAGGCCCTGTGGGTCTC-3' } \\
\text { 5'-GATGGCCTTTCTCACCAGGTT-3' }\end{array}$ & 149 \\
\hline GAPDH & $\begin{array}{l}\text { Forward } \\
\text { Reverse }\end{array}$ & $\begin{array}{l}\text { 5'-GGTGAAGGTCGGTGTGAACGGA-3' } \\
\text { 5'-TGTTAGTGGGGTCTCGCTCCTG-3' }\end{array}$ & 310 \\
\hline
\end{tabular}

miR, microRNA; SMA, smooth muscle actin; Col, collagen.
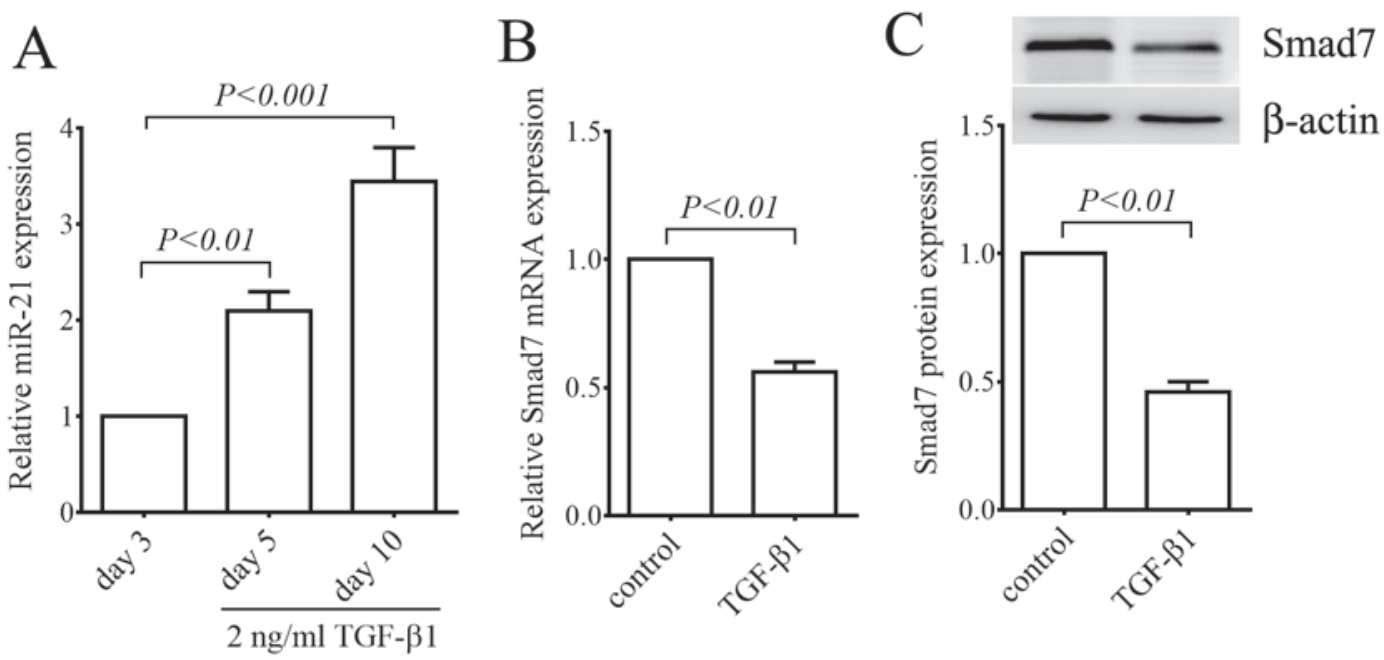

Figure 1. Expression of miR-21 and Smad7 in activated HSCs. (A) miR-21 expression in primary HSCs was significantly upregulated by TGF- $\beta 1$ in a time-dependent manner. Primary HSCs were cultured for 3 days, then incubated with $2 \mathrm{ng} / \mathrm{ml}$ TGF- $\beta 1$ for 2 days (day 5) and 7 days (day 10). Expression of miR-21 in HSCs was assessed by RT-qPCR. The level of miR-21 expression in untreated cells at day 3 was adjusted to 1 , expression at day 5 and day 10 following TGF- $\beta 1$ incubation was normalized to day 3 . U6 expression was used as an internal control (n=8). (B) TGF- $\beta 1$ alters expression of $S M A D 7$ in activated HSCs. Total RNA was isolated from the cells incubated with $2 \mathrm{ng} / \mathrm{ml}$ TGF- $\beta 1$ for 2 days, and subjected to RT-qPCR analysis. GAPDH was used as an internal control $(\mathrm{n}=8)$. (C) TGF- $\beta 1$ alters Smad7 protein content of activated HSCs. Total protein was isolated from the cells incubated with $2 \mathrm{ng} / \mathrm{ml}$ TGF- $\beta 1$ for 2 days, and subjected to western blot analysis. $\beta$-actin was used as an internal control $(n=8)$. The level of Smad7 (B) mRNA and (C) protein in control cells was adjusted to 1 , its expression after TGF- $\beta 1$ incubation was normalized to control cells. Data are presented as the mean \pm standard deviation. $\mathrm{P}<0.01$, $\mathrm{P}<0.001$ as indicated. miR, microRNA; HSC, hepatic stellate cells; TGF, transforming growth factor; RT-qPCR, reverse transcription-quantitative polymerase chain reaction.

of Smad7 and miR-21 mimics, and thus the ratio of Renilla to firefly luciferase in this group was significantly lower than in other groups $(\mathrm{P}<0.01$; Fig. 4). These observations indicated that miR-21 directly binds the 3'-UTR of Smad7.

\section{Discussion}

miR-21 is one of the most commonly and highly upregulated miRNAs in many cancers (12), and has been reported to contribute to lung, heart, and kidney fibrosis $(13,14)$. miR-21 was also recently reported to mediate ERK1 signaling and EMT by regulating SPRY2 and HNF4 $\alpha$ expression during liver fibrosis, suggesting that miR-21 may represent a potential biomarker of hepatic cirrhosis, and that inhibition miR-21 may prove therapeutically beneficial (18). However, the precise mechanism by which miR-21 participates in liver fibrosis remains to be determined.

Liver fibrosis is characterized by activation and transdifferentiation of HSCs to myofibroblasts $(1,2)$. HSCs are usually quiescent in healthy liver tissue, and thus termed 
A

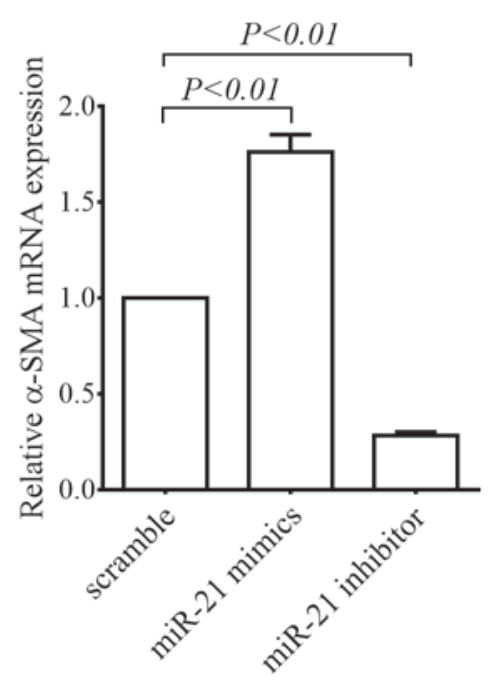

B
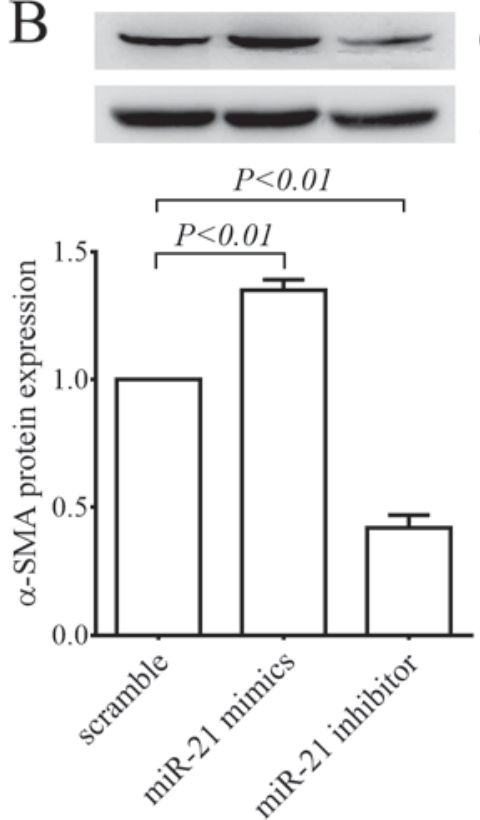

$\alpha$-SMA

$\beta$-actin

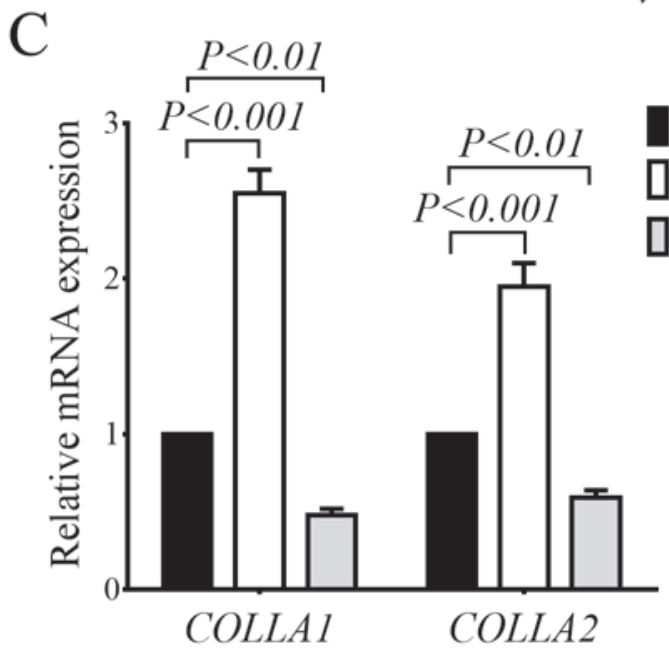

scramble

TmiR-21 mimics

UmiR-21 inhibitor

Figure 2. Effect of miR-21 on expression of $\alpha$-SMA, COLLA1 and COLLA2. (A) Effect of miR-21 mimics and inhibitor on expression of $\alpha$-SMA. Activated HSCs were incubated with $75 \mathrm{nM}$ scramble, miR-21 mimics or miR-21 inhibitor for $48 \mathrm{~h}$, then total RNA was isolated to measure $\alpha$-SMA mRNA levels ( $\mathrm{n}=8$ ). (B) Effect of miR-21 mimics and inhibitor on $\alpha$-SMA protein content. HSCs were treated, as in Fig. 2A, and total protein was isolated to detect $\alpha$-SMA content $(\mathrm{n}=8)$. (C) Effect of miR-21 mimics and inhibitor on expression of COLLA1 and COLLA2. The level of mRNA and protein in scramble cells was adjusted to 1 , the mRNA and protein expression following incubation with miR-21 mimics and inhibitor was normalized to scramble cells ( $\mathrm{n}=8$ ). Data are presented as the mean \pm standard deviation. $\mathrm{P}<0.01, \mathrm{P}<0.001$ as indicated. miR, microRNA; SMA, smooth muscle actin; COLLA, collagen type I alpha; HSCs, hepatic stellate cells.

vitamin A-storing adipogenic cells (25). However, upon liver injury, HSCs undergo a major phenotypic transition to become hepatic myofibroblasts. This transition is characterized by aberrant expression of $\alpha$-SMA, collagen I and the secretion of TGF- $\beta 1$, an important fibrogenic growth factor (25). TGF- $\beta$ has been demonstrated to promote miR-21 expression by enhancing formation of the R-Smad protein complex (15). Consistent with previous findings, the authors observed that incubating rat primary HSCs with $2 \mathrm{ng} / \mathrm{ml}$ TGF- $\beta 1$ significantly increased miR-21 expression in a time-dependent manner. Moreover, a previous study demonstrated that TGF- $\beta$ accelerates HSC transformation into myofibroblasts by increasing expression of $\alpha$-SMA and collagen (5). Furthermore, Liu et al (13) reported that miR-21 overexpression enhanced TGF- $\beta 1$-induced transcription of Fn and $\alpha$-SMA in pulmonary fibroblasts and, conversely, miR-21 knockdown attenuated TGF- $\beta 1$-dependent transcription of Fn and $\alpha$-SMA. In rat TGF- $\beta 1$-induced HSCs, similar results were observed. miR-21 mimics significantly enhanced expression of $\alpha$-SMA mRNA and protein, while a miR-21 inhibitor significantly suppressed expression of $\alpha$-SMA mRNA and protein. miR-21 was reported to promote collagen synthesis in high glucose-treated primary cardiac fibroblasts by targeting dual specific phosphatase 8 (24). The present study verified that expression of COLLA1 and COLLA2 mRNA in activated rat HSCs was regulated by miR-21, indicating that miR-21 serves a key role in the TGF- $\beta 1$-induced activation of HSCs.

Upon TGF- $\beta$ stimulation, Smad-7 transcription is usually induced by Smad-2/3 and Smad-4 (26), elevated Smad-7 in turn suppresses TGF- $\beta$-signaling through two 
A

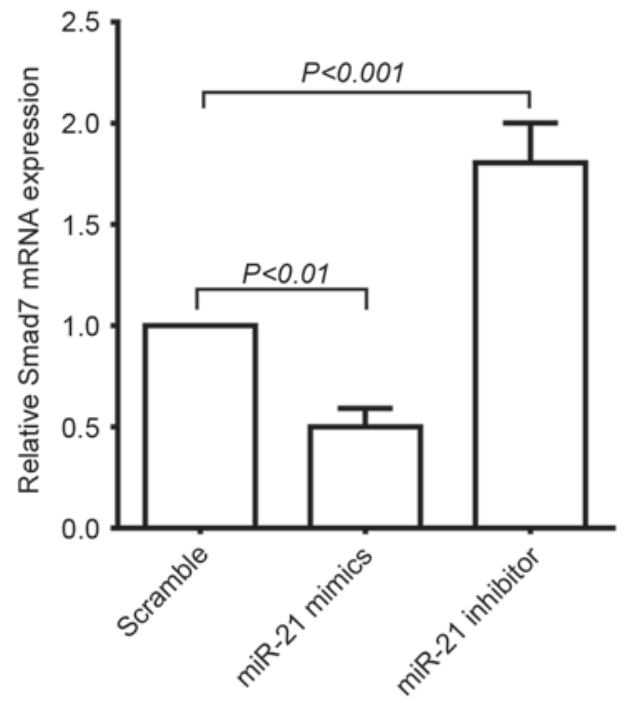

B
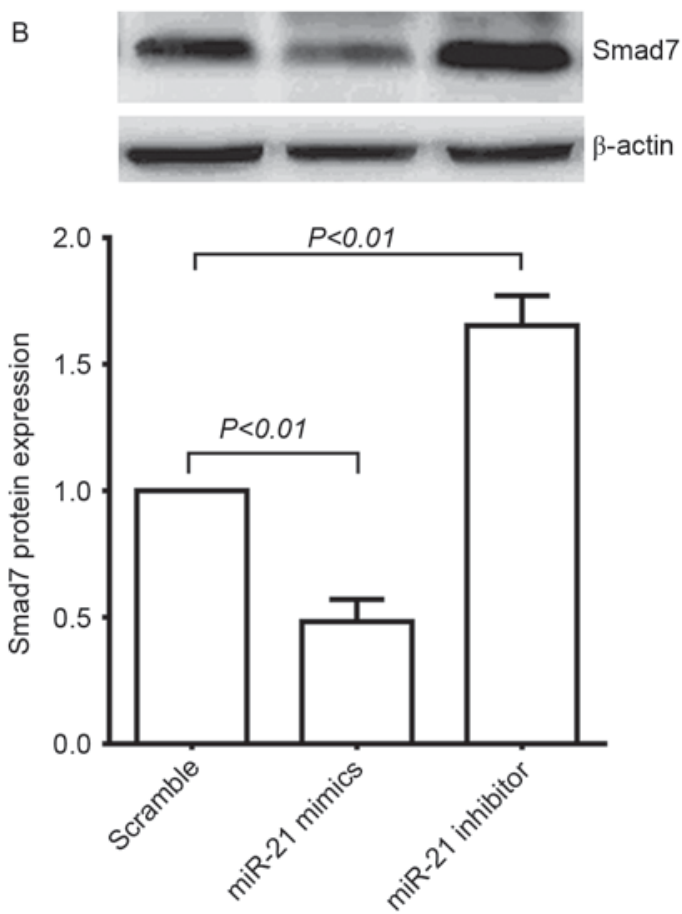

Figure 3. Effect of miR-21 on expression of SMAD7 mRNA and protein in activated HSCs. (A) Effect of miR-21 mimics and inhibitor on the expression of SMAD7 mRNA. HSCs were treated as described in Fig. 2A and reverse transcription-quantitative polymerase chain reaction analysis was carried out to measure SMAD7 mRNA expression (n=8). (B) Effect of miR-21 mimics and inhibitor on Smad7 protein expression. HSCs were treated as described in Fig. 2A $(\mathrm{n}=8)$. Data are presented as the mean \pm standard deviation. $\mathrm{P}<0.01, \mathrm{P}<0.001$ as indicated. miR, microRNA; HSCs, hepatic stellate cells.

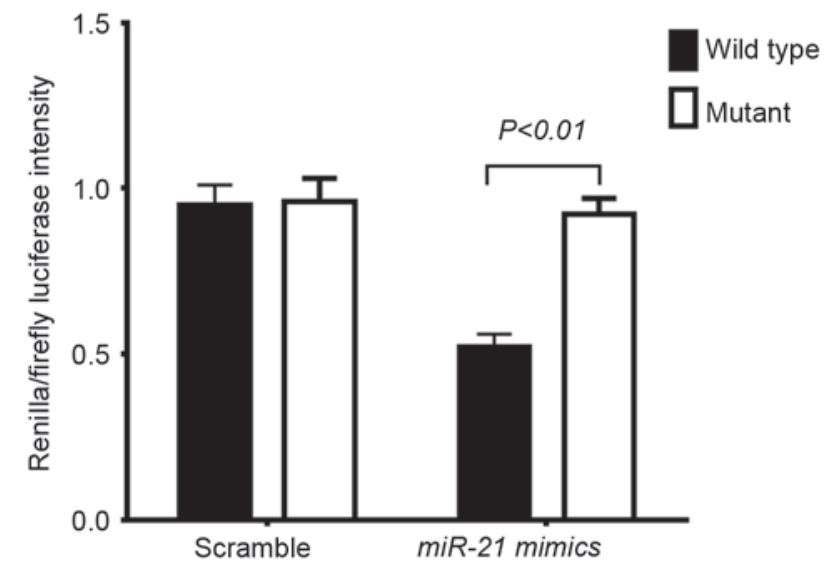

Figure 4. SMAD7 is a direct target of miR-21. HEK 293 cells were transfected with pMIR-reporter plasmid containing wild-type or mutant Smad7 3'-UTR, and co-transfected with miR-21 mimics or scramble miRNA. The activity of Renilla and firefly luciferase was measured. The ratio of Renilla/firefly luciferase activity was calculated $(n=8)$. Data are presented as the mean \pm standard deviation. $\mathrm{P}<0.01, \mathrm{P}<0.001$ as indicated. miR, microRNA.

major mechanisms: (1) Inhibition of the TGF- $\beta$ type I receptor (27) and (2) by interacting with Smurf2 to form an E3 ubiquitin ligase that degrades TGF- $\beta$ type I receptor (8). Smad7 overexpression was recently reported to inhibit HSC transdifferentiation and attenuate fibrosis, highlighting Smad7 as a promising target for antifibrotic treatment (9). Interestingly, in the current study, the Smad7 mRNA and protein levels were significantly reduced in rat HSCs incubated with TGF- $\beta 1$. Although this finding is not consistent with previous studies $(7,26)$, a recent Bian et al (3) recently reported that epigenetic repression of Smad7 by DNA methylation promotes HSC activation and liver fibrosis in rats. Thus, reduced $\mathrm{Smad} 7$ expression likely indicates the activation of HSCs by TGF- $\beta 1$. Moreover, increasing evidence suggest that in fibrosis miR-21 regulates synthesis of Smad7 protein $(1,13)$. The expression of Smad7 mRNA and protein was downregulated by miR-21 mimics, but upregulated by the miR-21 inhibitor in activated rat HSCs. More importantly, the authors further verified that miR-21 mimics can specifically bind the 3'-UTR of Smad7, which is consistent with a previous report (20). These results may help to explain how incubation with TGF- $\beta 1$ reduced Smad7 expression, because the inhibitory effect of elevated miR-21 on Smad7 expression may completely suppress the inducing effect of TGF- $\beta 1$ after $48 \mathrm{~h}$. These data provides further evidence that miR-21 acts as a profibrogenic miRNA by inhibiting Smad-7 expression, suggesting that miR-21/Smad7 signaling may be a promising and key target for the treatment of liver fibrosis.

In the current study, the authors did not verify whether elevated expression of $\alpha$-SMA, COLLA1 and COLLA2 in activated rat HSCs is caused by the repression of Smad7. However, Dooley et al (9) previously reported that Smad7-overexpressing BDL (ligation of the common bile duct) rats expressed less collagen and $\alpha$-SMA expression in the liver (28), while acetaldehyde upregulated expression of COL1A2 by 3.5 -fold through Smad7 in HSCs (29). Thus, these studies provide evidence that Smad7 can directly enhance expression of $\alpha$-SMA and collagen I in activated HSCs.

In conclusion, the authors demonstrated that miR-21 regulates expression of $\alpha$-SMA and collagen $I$ in rat TGF- $\beta 1$-activated HSCs by inhibiting Smad7 expression. The 
present study provides evidence that miR-21/Smad7 signaling serves an important role in the pathogenesis of liver fibrosis.

\section{Acknowledgements}

The current study was supported by the grants from the Natural Science Foundation of Zhejiang Province (grant no. LY14H030010) and the Wenzhou Science \& Technology Development Program (grant no. Y20120032).

\section{References}

1. Noetel A, Kwiecinski M, Elfimova N, Huang J and Odenthal M: microRNA are central players in anti- and profibrotic gene regulation during liver fibrosis. Front Physiol 3: 49, 2012.

2. Bataller R and Brenner DA: Liver fibrosis. J Clin Invest 115: 209-218, 2005.

3. Bian EB, Huang C, Wang H, Chen XX, Zhang L, Lv XW and Li J: Repression of Smad7 mediated by DNMT1 determines hepatic stellate cell activation and liver fibrosis in rats. Toxicol Lett 224: 175-185, 2014.

4. Yoshida $\mathrm{K}$ and Matsuzaki K: Differential regulation of TGF- $\beta$ /Smad signaling in hepatic stellate cells between acute and chronic liver injuries. Front Physiol 3: 53, 2012.

5. Gressner AM, Weiskirchen R, Breitkopf K and Dooley S: Roles of TGF-beta in hepatic fibrosis. Front Biosci 7: d793-d807, 2002.

6. Nakao A, Afrakhte M, Morén A, Nakayama T, Christian JL, Heuchel R, Itoh S, Kawabata M, Heldin NE, Heldin CH and ten Dijke P: Identification of Smad7, a TGFbeta-inducible antagonist of TGF-beta signalling. Nature 389: 631-635, 1997.

7. Derynck $R$ and Zhang YE: Smad-dependent and Smad-independent pathways in TGF-beta family signalling. Nature 425: 577-584, 2003.

8. Kavsak P, Rasmussen RK, Causing CG, Bonni S, Zhu H, Thomsen GH and Wrana JL: Smad7 binds to Smurf2 to form an E3 ubiquitin ligase that targets the TGF beta receptor for degradation. Mol Cell 6: 1365-1375, 2000.

9. Dooley S, Hamzavi J, Breitkopf K, Wiercinska E, Said HM, Lorenzen J, Ten Dijke P and Gressner AM: Smad7 prevents activation of hepatic stellate cells and liver fibrosis in rats. Gastroenterology 125: 178-191, 2003.

10. Ambros V: The functions of animal microRNAs. Nature 431: 350-355, 2004

11. Croce CM: Causes and consequences of microRNA dysregulation in cancer. Nat Rev Genet 10: 704-714, 2009.

12. Bonci D: MicroRNA-21 as therapeutic target in cancer and cardiovascular disease. Recent Pat Cardiovasc Drug Discov 5: $156-161,2010$.

13. Liu G, Friggeri A, Yang Y, Milosevic J, Ding Q, Thannickal VJ, Kaminski N and Abraham E: miR-21 mediates fibrogenic activation of pulmonary fibroblasts and lung fibrosis. J Exp Med 207: $1589-1597,2010$.

14. Zarjou A, Yang S, Abraham E, Agarwal A and Liu G: Identification of a microRNA signature in renal fibrosis: Role of miR-21. Am J Physiol Renal Physiol 301: F793-F801, 2011.
15. Davis BN, Hilyard AC, Lagna G and Hata A: SMAD proteins control DROSHA-mediated microRNA maturation. Nature 454: 56-61, 2008.

16. Zhong X, Chung AC, Chen HY, Meng XM and Lan HY: Smad3-mediated upregulation of miR-21 promotes renal fibrosis. J Am Soc Nephrol 22: 1668-1681, 2011.

17. Wei J, Feng L, Li Z, Xu G and Fan X: MicroRNA-21 activates hepatic stellate cells via PTEN/Akt signaling. Biomed Pharmacother 67: 387-392, 2013

18. Zhao J, Tang N, Wu K, Dai W, Ye C, Shi J, Zhang J, Ning B, Zeng $X$ and Lin Y: MiR-21 simultaneously regulates ERK1 signaling in HSC activation and hepatocyte EMT in hepatic fibrosis. PLoS One 9: e108005, 2014.

19. Marquez RT, Bandyopadhyay S, Wendlandt EB, Keck K, Hoffer BA, Icardi MS, Christensen RN, Schmidt WN and McCaffrey AP: Correlation between microRNA expression levels and clinical parameters associated with chronic hepatitis C viral infection in humans. Lab Invest 90: 1727-1736, 2010.

20. Wang JY, Gao YB, Zhang N, Zou DW, Wang P, Zhu ZY, Li JY, Zhou SN, Wang SC, Wang YY and Yang JK: miR-21 overexpression enhances TGF- $\beta 1$-induced epithelial-to-mesenchymal transition by target smad7 and aggravates renal damage in diabetic nephropathy. Mol Cell Endocrinol 392: 163-172, 2014.

21. Hinz B, Celetta G, Tomasek JJ, Gabbiani G and Chaponnier C: Alpha-smooth muscle actin expression upregulates fibroblast contractile activity. Mol Biol Cell 12: 2730-2741, 2001.

22. Livak KJ and Schmittgen TD: Analysis of relative gene expression data using real-time quantitative PCR and the 2(-Delta Delta C(T)) method. Methods 25: 402-408, 2001.

23. Gong C, Nie Y, Qu S, Liao JY, Cui X, Yao H, Zeng Y, Su F, Song E and Liu Q: miR-21 induces myofibroblast differentiation and promotes the malignant progression of breast phyllodes tumors. Cancer Res 74: 4341-4352, 2014.

24. Liu S, Li W, Xu M, Huang H, Wang J and Chen X: Micro-RNA 21Targets dual specific phosphatase 8 to promote collagen synthesis in high glucose-treated primary cardiac fibroblasts. Can J Cardiol 30: 1689-1699, 2014.

25. Friedman SL: Hepatic stellate cells: Protean, multifunctional, and enigmatic cells of the liver. Physiol Rev 88: 125-172, 2008.

26. Stopa M, Anhuf D, Terstegen L, Gatsios P, Gressner AM and Dooley S: Participation of Smad2, Smad3, and Smad4 in transforming growth factor beta (TGF-beta)-induced activation of Smad7. THE TGF-beta response element of the promoter requires functional Smad binding element and E-box sequences for transcriptional regulation. J Biol Chem 275: 29308-29317, 2000.

27. Massagué J and Chen YG: Controlling TGF-beta signaling. Genes Dev 14: 627-644, 2000.

28. Meindl-Beinker NM and Dooley S: Transforming growth factor-beta and hepatocyte transdifferentiation in liver fibrogenesis. J Gastroenterol Hepatol 23 (Suppl 1): S122-S127, 2008.

29. Reyes-Gordillo K, Shah R, Arellanes-Robledo J, Hernández-Nazara Z, Rincón-Sánchez AR, Inagaki Y, Rojkind M and Lakshman MR: Mechanisms of action of acetaldehyde in the up-regulation of the human $\alpha 2$ (I) collagen gene in hepatic stellate cells: Key roles of Ski, SMAD3, SMAD4, and SMAD7. Am J Pathol 184: 1458-1467, 2014. 